Miljan Jović

Nebojša Milićević https://doi.org/10.46630/gpsi.17.2020.04

Miodrag Milenović

Miroslav Komlenić

Departman za psihologiju,

Filozofski fakultet,

Univerzitet u Nišu

Niš, Srbija

\title{
PROVODLJIVOST KOŽE I PROMENE U IZRAŽENOSTI POZITIV- NOG I NEGATIVNOG AFEKTA IZAZVANE GLEDANJEM ISEČKA IZ FILMA U ODNOSU NA OPTIMIZAM I PESIMIZAM ${ }^{2}$
}

\begin{abstract}
Apstrakt
Cilj ovog rada je ispitivanje povezanosti između psihogalvanskog refleksa i neprijatnog afekta, indukovanog filmom, kao i razlika između optimista i pesimista u pogledu indukcije neprijatnog afekta. Uzorak su činila 42 studenta Filozofskog fakulteta u Nišu (muškaraca, $n=4$; žena, $n=38$ ) starosti između 18 i 20 godina $(M=19, S D=$ 0.54). Korišćeni su sledeći instrumenti: revidirana skala životne orijentacije (LOT-R), kratka skala introspekcije raspoloženja (BMIS), kao i osmokanalni poligraf ProComp Infiniti verzija 4.0. Stimulus je bio klip iz filma „Sofijin izbor”, a ispitanici su pre isečka iz filma gledali neutralan stimulus koji je služio kao kontrolna mera za snimanje bazičnog nivoa provodljivosti kože ispitanika. Podaci su obrađivani $t$-testom za nezavisne uzorke (za razlike između optimista i pesimista) i $t$-testom za zavisne uzorke (za razlike pre i posle gledanja isečka). Iz rezultata ovog rada možemo da zaključimo da se raspoloženje optimista, posle gledanja isečka iz filma usmerenog na indukciju neprijatnog afekta, menja više nego raspoloženje pesimista $(p=.000)$. Preciznije, raspoloženje optimista se više „kvari““ posle gledanja pomenutog isečka iz filma, dok se raspoloženje pesimista ne menja statistički značajno $(p=.367)$. Provodljivost kože se menja statistički značajno i kod optimista $(p=.001)$ i kod pesimista $(p=.005)$. Možemo da zaključimo da se u ovom radu pokazalo da je indukcija afekta različita za ove dve podgrupe našeg uzorka. S obzirom na ovaj podatak, u narednim radovima koji se bave indukcijom afekta, trebalo bi voditi računa i o ovoj varijabli koja bi mogla biti konfundirajuća u ovakvim istraživanjima.
\end{abstract}

Ključne reči: optimizam-pesimizam, film, indukcija emocija, negativni afekat, psihogalvanski refleks.

\footnotetext{
${ }^{1}$ ana.jovancevic@filfak.ni.ac.rs

${ }^{2}$ Istraživanje je urađeno u okviru internog projekta NV 183/1-16-9-01: Primenjena psihologija u funkciji kvaliteta života pojedinca u zajednici, koji finansira Filozofski fakultet Univerziteta u Nišu.
} 


\section{Uvod}

Kada govorimo o filmovima, važno je pomenuti da televizija (a u sklopu nje i filmski i serijski program) zauzima jedan veliki deo dana prosečnog građanina Srbije. Tako statistički podaci, za 2015/2016. godinu, pokazuju da je Srbija druga zemlja po redu u Evropi po prosečnom dnevnom vremenu provedenom ispred televizora (Statista Research Department, 2018) i da ljudi u Srbiji provode prosečno skoro pet i po sati ispred televizora u toku jednog dana (ili 317 minuta). Ovaj podatak je važno pomenuti jer on ukazuje na to da je televizija, kao agens socijalizacije, veoma prisutna u našoj zemlji. Dalje, ukoliko televizija, toliko često prisutna u našim životima, može da utiče na naše psihičko stanje i na naše ponašanje - na šta brojni radovi iz psihologije ukazuju (npr., Appel, Krause, Gleich, \& Mara, 2016; Gross \& Levenson, 1995; Iguarta Perosanz \& Paez Rovira, 1998) - važno je znati na koji način ona to čini i umanjiti sadržaje koji ostvaruju negativan uticaj na nas, a povećati količinu sadržaja koji na nas imaju pozitivan uticaj. Treba imati u vidu i fenomen ,,bindge watching “ („Binge-watching”, 2019), fenomen koji označava „maratonsko“ gledanje serija, odnosno, uglavnom više epizoda jedne serije uzastopno, bez prekida. Ovaj fenomen pominjemo radi isticanja prisustva televizije u životima ljudi, i samim tim koliko je važno proučavati sve njene aspekte, uključujući i filmove.

$\mathrm{Na}$ početku izlaganja o psihologiji filma počećemo od jednog od verovatno najuticajnih autora u ovoj oblasti, od Rudolfa Arhajma. Arhajm (Arnheim, 1993) na početku svoje knjige „Film kao umetnost“ film upoređuje sa ostalim vrstama umetnosti, sa slikarstvom, plesom i muzikom, i navodi da je njihova najveća sličnost $u$ tome što su sve one zapravo medijumi, koji mogu, ali ne moraju, biti upotrebljeni za stvaranje važnih umetničkih doprinosa društvu. Arhajm ovo navodi zbog toga što je, $u$ vreme u kome je on stvarao, veliki broj ljudi verovao da film zapravo nije umetnost.

Danas je situacija već drugačija. Film svi prihvataju kao jednu vrstu umetnosti („Sedma umetnost”), a osim toga, ima i brojnih psiholoških istraživanja vezanih za film. Grupa istraživanja vezanih za film, a koja nas interesuje u ovom radu, jeste ona koja se odnosi na mogućnost indukovanja emocija putem filma. Naime, postoje brojni radovi koji pokazuju da se emocije mogu indukovati putem filmova, kao i isečaka iz istih. Gros i Levinson (Gross \& Levenson, 1995) uspešno su klipovima iz filmovima indukovali osećanje zabavljenosti, tugu i neutralno stanje. Autori čak pominju da su filmovi verovatno najefikasija sredstva indukcije emocije, efikasnije od drugih laboratorijskih metoda (mirisi, zamišljene ili ponovo preživljavane scene, muzika, hipnoza i sl.; Rottenberg, Ray, \& Gross, 2007). Studije koje se bave indukcijom emocija putem filmova su pokazale da filmovi mogu da indukuju anskioznost (Pillard, McNair, \& Fisher, 1974), ljutnju (Brown et al., 1977, prema Hagemann et al., 1999), depresivno raspoloženje (van Rooijen \& Vlaander, 1984) i tugu (Engel, Frader, Barry, \& Morrow, 1984). U jednoj studiji (Philippot, 1993) autor je prezentovao ispitanicima segmente komercijalnih filmova, filmova privlačnim širokim narodnim masama, i uspešno indukovao više emocija (ljutnju, odvratnost, tugu, sreću i strah). 
Postoje neki autori koji ispituju kojim mehanizmom film indukuje emocije. Tako je, na primer, jedna grupa autora otkrila da dramatični filmski stimulusi mogu da indukuju emocije i to preko empatije ispitanika (Davis, Hull, Young, \& Warren, 1987). Tačnije, ovi autori su otkrili da kognitivna empatija - vrsta empatije koja podrazumeva kapacitet osobe da zauzme psihološku perspektivu druge osobe (Dziobek et al., 2008) - ima važnu ulogu u prijatnim emocionalnim reakcijama na filmske stimuluse, dok emotivna empatija - empatija koja se odnosi na emotivne reakcije jedne osobe na emocionalno stanje druge osobe (Dziobek et al., 2008) - ima važnu ulogu u doživljavanju neprijatnih emocija na filmske stimuluse. Jedna druga grupa autora pokazuje da je mehanizam preko koga film indukuje emociju zapravo identifikacija sa filmskim likovima (Tannenbaum \& Gaer, 1964).

Postoje istraživanja koja su se usmerila na fiziološke aspekte emocija, a jedan od tih fizioloških aspekata je i provodljivost kože. Provodljivost kože (SC Skin conductance) jeste mera aktivnosti znojne žlezde na površini kože, najčešće na rukama (Jovanović i Jovanović, 2005). Ova mera često se sreće i pod nazivima elektrodermalni odgovor (EDR), bazični odgovor kože (BSR - Basic skin response), Galvanski odgovor kože (GSR - Galvanic skin response), simpatički odgovor kože (SSR - Sympathethic skin response), nivo provodljivosti kože (SCL - Skin conductance level), dok je u domaćoj literaturi verovatno najpoznatiji naziv psihogalvanski refleks ili psihogalvanska reakcija (PGR; Boucsein, 1992; Jovanović i Jovanović, 2005; Prokasy \& Raskin, 1973).

Provodljivost kože je osetljiv psihofiziološki indeks promena koje su povezane sa emotivnim i kognitivnim stanjima, a do kojih dolazi usled aktivnosti simpatičkog nervnog sistema (Critchley, 2002). Veliki broj autora izveštava o tesnoj vezi između emocionalnih reakcija i provodljivosti kože (Edelberg, 1972; Kim, Bang, \& Kim, 2004; Lanat'a, Valenza, \& Scilingo, 2012). Kada je čovek izložen emocionalnim ili stresnim stimulusima dolazi do aktivacije simpatičkog nervnog sistema pod čijom kontrolom je i aktivnost znojnih žlezda (Silverthorn, 2009). Usled dejstva simpatikusa dolazi do pojačane aktivnosti znojnih žlezda koje izlučuju slani rastvor usled kojeg dolazi do povećane vlažnosti dlanova. Znoj sadrži u sebi električno provodljive soli i što je koža vlažnija od znoja, njena provodljivost je veća (Jovanović i Jovanović, 2005).

Shodno tome, mera provodljivosti kože koristi se kao indikator emotivnih stanja. Ipak, treba uzeti u obzir i to da mera o provodljivosti kože, iako pokazuje promene u provodljivosti, ne može tačno da detektuje u kom emotivnom stanju je ispitanik, pa se zbog toga savetuje da se uz meru dobijenu putem elektroda koje mere provodljivost kože uzme i subjektova procena o emotivnom stanju u kome se nalazi za vreme merenja (Boucsein, 1992). Tako je slika o emotivnom stanju i fiziološkim promenama do kojih dolazi tom prilikom jasnija i kompletnija.

Postoje takođe dokazi da film adekvatno indukuje sve aspekte emocija, uključujući ponašajnu komponentu, ali i automatske i centralne fiziološke reakcije (Gross \& Levenson, 1995). Osim što su autori potvrdili da filmovi mogu izazvati emocije putem upitnika samoprocene, neki od njih su i potvrdili da filmovi mogu da indukuju fiziološke reakcije na filmove, i to merene putem EMR-a, i to, između ostalog, mogu da izmene otkucaje srca kao i provodljivost kože (Mewborn \& Rogers, 1979). 
Osim filma, druga varijabla u našem istraživanju je i optimizam-pesimizam. Optimizam i pesimizam u ovom istraživanju shvaćeni su kao dispozicije ličnosti, u skladu sa shvatanjima autora skale koju koristimo radi operacionalizacije ovih varijabli (Scheier, Weintraub, \& Carver, 1986). Dispozicijski optimizam i pesimizam se zapravo odnose na opšte očekivanje osobe da će im se dogoditi više dobrih nego loših stvari (u slučaju optimizma) ili više loših nego dobrih stvari (u slučaju pesimizma; Carver, Scheier, \& Segerstrom, 2010, prema Rijavec i Ivanković, 2017). Naime, prethodne studije pokazuju da se optimisti i pesimisti razlikuju u pogledu niza psiholoških osobina i odlika. Pre svega, istraživanja pokazuju da se optimisti i pesimisti razlikuju u pogledu toga kako reaguju u stresnim situacijama (Scheier et al., 1986). Ovi podaci su bitni za naš rad jer su neprijatne emocije sastavni deo stresnih situacija, a u ovom radu se bavimo upravo negativnim afektom. Postoji i niz drugih studija koje govore o velikim razlikama između optimista i pesimista (npr., Ausbrooks, Thomas, \& Williams, 1995; Blankstein, Flett, \& Koledin, 1991). Prethodni radovi pokazuju da je optimizam, među univerzitetskim studentima, povezan sa: nižim nivoom nivoa hroničnog besa i sa manjim potiskivanjem besa (Ausbrooks et al., 1995), sa manje svađa sa drugim ljudima i sa boljim percipiranim psihosocijalnim prilagođavanjem (Blankstein et al., 1991), sa nižim nivoom stresa (Chang, 1998a; Chang, 1998b; O’Brien, van Egeren, \& Mumby, 1995), manje depresivnih simptoma i sa većim zadovoljstvom životom (Chang, 1998a; Chang, 1998b), sa manje svakodnevnih svađa (Nelson, Karr, \& Coleman, 1995), kao i sa manje izraženom anskioznošću kao crtom (Schuller, 1995; Sumi, Hofie, \& Hayakava, 1997). Rezultati prethodnih radova takođe pokazuju da je optimizam kod odraslih povezan sa: manjim oscilacijama u raspoloženju (Fontaine \& Seal, 1997), internim lokusom kontrole (Guarnera \& Williams, 1987), nižim nivoom stresa (Khoo \& Bishop, 1997) i sa većim subjektivnim blagostanjem (Khoo \& Bishop, 1997; Sweetman, Munz, \& Wheeler, 1993), nižom anksioznošću kao i sa većim zadovoljstvom poslom (Long, Kahn, \& Schutz, 1992) i nižom depresivnošću (Marshall \& Lang, 1990). Na osnovu svih navedenih istraživanja može se pretpostaviti da bi ispitanici kod kojih je istraženiji optimizam trebalo da doživljavaju više pozitivnih emocionalnih stanja. Sve ove rezultate možemo da sumiramo u jedan zaključak da optimisti doživljavaju manje negativnih, a više pozitivnih emocionalnih stanja od pesimista. Takođe, kada su u pitanju optimisti i pesimisti, interesantni nalazi prethodnih radova, koji su ispitivali uspešnost rešavanja zadataka kod optimista i pesimista, pokazuju da pesimisti funkcionišu najbolje onda kada su im indukovana neprijatna rasploženja koja sa sobom nose pozitivnije predstave o tome "šta bi sve moglo biti" (prefraktalno razmišljanje - koje se odnosi upravo na razmišljanje osobe u smeru toga "šta bi sve moglo biti”), dok optimisti najbolje funkcionišu u situacijama gde im se indukuje prijatno raspoloženje (Sanna, 1998).

Uzevši u obzir sve rečeno u ovom teorijskom delu, možemo reći da je cilj ovog istraživanja ispitivanje postojanja povezanosti između psihogalvanskog refleksa i neprijatnog afekta, indukovanog putem filma, kao i ispitivanje razlika između optimista i pesimista u pogledu indukcije neprijatnog afekta. 


\section{Metod}

\section{Uzorak i postupak}

Uzorak je činilo 42 studenata prve godine psihologije sa Filozofskog fakulteta u Nišu. U uzorku je bilo 4 muškarca i 38 žena starosti između 18 i 20 godina ( $M=$ 19 godina, $S D=0.541)$. Pre odabira konačnog uzorka za ovo istraživanje, iz prvobitnog uzorka $(N=80)$, odabrani su samo ekstremni optimisti i ekstremni pesimisti, tako da je konačnom uzorku bio podjednak broj ispitanika kod kojih je dominantan optimizam odnosno pesimizam.

Procedura istraživanja se odvijala tako što su ispitanici popunili upitnik za procenu optimizma-pesimizma. Iz početnog uzorka je odabrano samo 20 ispitanika koji imaju ekstremno izražen optimizam i 20 onih koji imaju izražen pesimizam.

Odabrani ispitanici su popunjavali upitnik koji procenjuje trenutno raspoloženje. Potom su gledali video material koji predstavlja neutralan stimulus. Nakon toga su gledali isečak iz filma Sofijin izbor radi indukcije neprijatnog afekta. Za ovaj isečak su prethodna istraživanja pokazala da indukuje negativan afekat (Janjić \& Goljović, 2019), a sama scena ilustruje ophođenje prema Jevrejima tokom Drugog svetstog rada, i u njoj majku nemački oficir prisiljava da odabere koje će od svoje dvoje dece zadržati. Posle gledanja ovog isečka ispitanici su ponovo popunjavali upitnik za procenu trenutnog raspoloženja kako bismo utvrdili da li dolazi do promena u raspoloženju nakon odgledanog videa. Takođe je ispitanicima bio meren PGR kako u toku gledanja neutralnog stimulusa tako i u toku gledanja isečka iz filma Sofijin izbor.

\section{Instrumenti}

Revidirana skala životne orijentacije (Life orientation test - Revised: LOTR; Scheier, Carver, \& Bridges, 1994) radi operacionalizacije optimizma-pesimizma. Ovaj upitnik sadrži 10 stavki, od kojih se 3 stavke odnose na pesimizam, 3 na optimizam, dok su preostale 4 stavke filteri i služe za odvlačenje pažnje ispitanika od prave namene datog upitnika. Format odgovora na stavke ovog upitnika je petostepena skala Likertovog tipa gde 1 označava "U potpunosti se slažem" dok 5 označava "Ni malo se ne slažem". Primer stavke: "U najgorim trenucima obično očekujem najpozitivniji ishod". Pouzdanost skale je zadovoljavajuća (pesimizam: $\alpha=.818$; optimizam: $\alpha=.75$ ).

Radi operacionalizacije raspoloženja ispitanika korišćena je kratka skala introspekcije raspoloženja (Brief Mood Introspection Scale: BMIS; Mayer, \& Gaschke, 2013). Skala ima 17 tvrdnji, od kojih se 16 odnosi na različita raspoloženja, tačnije ispitanicima su ponuđena različita raspoloženja, a od njih se traži da označe koliko se tako osećaju u datom trenutku (Na primer: Živahno, Tužno, Zadovoljno i slično), dok 17-a tvrdnja operacionalizuje da li je raspoloženje ispitanika generalno gledano prijatno ili neprijatno. Format odgovora na prvih 16 stavki je četvorostepena skala Likertovog tipa, gde 1 označava "Uopšte se ne osećam tako", dok 4 označava "U potpunosti se tako osećam". Format odgovora na 17-u stavku je dvadesetostepe- 
na skala Likertovog tipa, gde -10 označava Veoma neprijatno raspoloženje dok 10 označava Veoma prijatno raspoloženje. Pouzdanost skale je zadovoljavajuća (pozitivan afekat: $\alpha=.746$; negativan afekat: $\alpha=.638$ ).

Provodljivost kože ispitanika merena je putem osmokanalnog poligrafa ProComp Infiniti verzija 4.0 (uz prateći softver BioGraph Infiniti ; Thought Technology, 2007). Korišćeni su senzori SC-Flex/Pro.

\section{Stimulusi}

U istraživanju su korišćena dva tipa stimulusa - neutralni i stimulusi negativne valence.

1) Stimulus je bio klip iz filma "Sofijin izbor" za koji se u ranijem radu sprovedenom od strane studenata Filozofskog fakulteta u Nišu pokazalo da indukuje neprijatan afekat (Janjić \& Goljović, 2019). ${ }^{3}$ Video je u trajanju od 5 minuta i 13 sekundi.

2) Ispitanici su pre gledanja isečka iz filma gledali neutralan stimulus, snimak vodopada sa pratećom umirujućom melodijom, koji ih je dovodio $\mathrm{u}$ stanje relaksiranosti i koji je služio kao kontrolna mera za snimanje bazičnog nivoa provodljivosti kože ispitanika.

\section{Metode analize podataka}

Podaci su obrađeni korišćenjem $t$-testa za zavisne, kao i $t$-testa za nezavisne uzorke. Naime, za ispitivanje razlika između optimista i pesimista korišćen je $t$-test za nezavisne uzorke, dok je za ispitivanje razlika kod istih ispitanika u pogledu pozitivnog i negativnog afekta, kao i u pogledu psihogalvanskog refleksa, pre i posle gledanja isečka iz filma, korišćen $t$-test za zavisne uzorke.

\section{Rezultati}

Tabela 1

Razlike u stepenu izraženosti prijatnih emocija, neprijatnih emocija i provodljivosti kože pre i posle prikazivanja filma kod optimista

\begin{tabular}{lccccc}
\hline \multicolumn{1}{c}{ Varijable } & $t(20)$ & Pre filma & Posle filma & $\begin{array}{c}\text { Razlika aritmetičkih } \\
\text { sredina }\end{array}$ & $\mathrm{p}$ \\
\hline Prijatne emocije & 5.54 & 2.70 & 2.39 & 0.32 & .000 \\
Neprijatne emocije & -1.46 & 2.47 & 2.59 & -0.12 & .137 \\
Provodljivost kože & -4.10 & 6.19 & 7.22 & -1.03 & .001 \\
\hline
\end{tabular}

Napomena . Pre filma = AS izraženosti pre filma; Posle filma = AS izraženosti posle filma.

\footnotetext{
${ }^{3}$ https://www.youtube.com/watch?v=DZ9bht5H2p4
} 
Rezultati su pokazali da postoje statistički značajne razlike u izraženosti prijatnih emocija kod optimista pre i posle gledanja odlomka iz filma. Razlika je statistički značajna na nivou $p<.001$ i pokazuje da su prijatne emocije kod optimista izraženije pre gledanja odlomka iz filma, dok se njihova izraženost statistički značajno umanjuje nakon odgledanog odlomka.

Rezultati takođe pokazuju da je promena u provodljivosti kože kod ispitanika iz ove grupe značajna, i to na nivou $p<.001$. Razlike idu u korist provodljivosti kože posle gledanja isečka iz filma.

Tabela 2

Razlike u stepenu izraženosti prijatnih emocija, neprijatnih emocija i provodljivosti kože pre i posle prikazivanja filma kod pesimista

\begin{tabular}{lccccc}
\hline Varijable & $t(20)$ & Pre filma & Posle filma & $\begin{array}{c}\text { Razlika aritmetičkih } \\
\text { sredina }\end{array}$ & $\mathrm{p}$ \\
\hline Prijatne emocije & 0.93 & 2.38 & 2.35 & 0.03 & .367 \\
Neprijatne emocije & 0.57 & 2.51 & 2.48 & 0.03 & .576 \\
Provodljivost kože & -3.19 & 6.33 & 7.19 & -0.86 & $\mathbf{. 0 0 5}$ \\
\hline
\end{tabular}

Napomena . Pre filma = AS izraženosti pre filma; Posle filma = AS izraženosti posle filma.

Rezultati su pokazali da postoje statistički značajne razlike u izraženosti provodljivosti kože prilikom gledanja kontrolnog stimulusa i prilikom gledanja odlomka iz filma kod pesimista. Razlika je statistički značajna na nivou $p<.01$ i pokazuje da je provodljivost kože veća prilikom gledanja odlomka.

Tabela 3

Razlike u stepenu izraženosti prijatnih emocija, neprijatnih emocija i provodljivosti kože pre i posle prikazivanja filma kod optimista i pesimista

\begin{tabular}{lccccc}
\hline \multicolumn{1}{c}{ Varijable } & $t(40)$ & Optimisti & Pesimisti & $\begin{array}{c}\text { Razlika aritmetičkih } \\
\text { sredina }\end{array}$ & $\mathrm{p}$ \\
\hline Pozitivan afekat pre filma & 4.09 & 2.70 & 2.38 & 0.32 & .000 \\
Pozitivan afekat posle filma & 0.45 & 2.39 & 2.35 & 0.04 & .653 \\
Negativan afekat pre filma & -0.40 & 2.47 & 2.51 & 0.04 & .714 \\
Negativan afekat posle filma & 0.95 & 2.59 & 2.48 & 0.11 & .347 \\
PGR pre filma & 0.19 & 6.19 & 6.33 & -0.14 & .852 \\
PGR posle filma & 0.17 & 7.22 & 7.19 & 0.03 & .972 \\
\hline
\end{tabular}

Napomena . Optimisti $=$ AS izraženosti kod optimista; Posle filma $=$ AS izraženosti kod pesimista.

Rezultati su pokazali da postoje statistički značajne razlike između optimista i pesimista u izraženosti prijatnih emocije pre gledanja odlomka iz filma. Naime, 
prijatne emocije izmerene pre gledanja odlomka iz filma izraženije su kod optimista. Navedena razlika je statistički značajna na nivou $p<.001$.

\section{Diskusija}

Usled nedostataka prethodnih radova koji se bave reakcijama optimista i pesimista na neprijatne filmske stimuluse, cilj ovog istraživanja je bilo ispitivanje postojanja povezanosti između psihogalvanskog refleksa i neprijatnog afekta, indukovanog putem filma, kao i ispitivanje razlika između optimista i pesimista u pogledu indukcije neprijatnog afekta.

Rezultati ovog rada pokazuju, pre svega da postoje statistički značajne razlike u pogledu izraženosti prijatnih emocija kod optimista pre i posle gledanja odlomka iz filma. Ovi rezultati nam ukazuju na to da se kod optimista ne menjaju značajno neprijatne emocije posle gledanja filma. Naime, iako su one izraženije posle gledanja filma, ova promena ipak nije značajna. Međutim, prijatne emocije su manje izražene posle gledanja isečka iz filma usmerenog na neprijatne emocije. Preciznije, na osnovu ovih podataka zaključujemo da se kod optimista dobro raspoloženje kvari posle gledanja isečka iz filma, što je u skladu sa nalazima prethodnih radova koji pokazuju da je film u stanju da indukuje razne neprijatne emocije kod ispitanika, tačnije da pokvari njihovo raspoloženje (Brown et al., 1977, prema Hagemann et al., 1999; Engel et al., 1984; Pillard et al., 1974; van Rooijen and Vlaander, 1984). Dakle, iz rezultata dobijamo podatak da su kod optimista vrednosti na skali prijatnih emocija niže posle gledanja isečka iz filma, u odnosu na skor na ovoj skali pre gledanja isečka iz filma. Takođe, rezultati su pokazali da postoje statistički značajne razlike u izraženosti prosečne provodljivosti kože prilikom gledanja kontrolnog stimulusa i prilikom gledanja odlomka iz filma kod optimista. Razlika je statistički značajna i pokazuje da je provodljivost kože veća prilikom gledanja odlomka iz filma. Ovi rezultati su u skladu sa nalazima prethodnih radova koji pokazuju da film i filmski odlomci dovode do promene u emotivnom stanju ispitanika, i to ne samo na psihološkom već i na fiziološkom planu (Gross \& Levenson, 1995; Mewborn \& Rogers, 1979). Iako samo na osnovu provodljivosti kože ne možemo da znamo tačno emocionalno stanje ispitanika, provodljivost kože, uz još neke mere, može da nam da važne podatke vezane za emocionalno stanje ispitanika, a predstavlja pre svega fiziološku "potvrdu" određene emocije kod ispitanika. Dakle, na osnovu svih ovih podataka možemo da izvedemo zaključak da je kod optimista raspoloženje opalo i postalo neprijatnije, što je praćeno promenama u provodljivosti kože.

Rezultati ovog rada dalje pokazuju da postoje statistički značajne razlike u izraženosti provodljivosti kože prilikom gledanja kontrolnog stimulusa i prilikom gledanja odlomka iz filma kod pesimista. Ovo je takođe u skladu sa nalazima prethodnih radova koji pokazuju da film i filmski odlomci dovode do promene u emotivnom stanju ispitanika, i to ne samo na psihološkom već i na fiziološkom planu (Gross \& Levenson, 1995; Mewborn \& Rogers, 1979). Međutim, raspoloženje pesimista se ne menja posle gledanja odlomka iz filma. Kako bi preciznije interpretirali razlike u 
rezultatima između pesimista i optimista, ispitali smo i razlike između ove dve podgrupe ispitanika. Interesantan podatak koji takođe vidimo iz prethodne tabele, jeste da se neprijatne emocije kod pesimista čak i smanjuju posle gledanja isečka iz filma (iako ne značajno), što bi moglo da se objasni time što pesimisti, osobe koje inače stvari gledaju negativno, sada bivaju izloženi jednoj neprijatnoj filmskoj sceni kakve su se u našoj istoriji realno dešavale (u filmu se radi o maltretiranju i progonu Jevreja tokom Drugog svetskog rata). Naime, pesimisti možda, kroz ovaj isečak, izlaze iz svoje perspektive i shvataju da postoje realno gore stvari od onih koje oni vide oko sebe i u svom bliskom okruženju, tj. verovatno je u pitanju i schadenfreude (,Schadenfreude“, 2019), odnosno osećaj zadovoljstva prilikom svedočenja nesrećama drugih ljudi ${ }^{4}$. Takođe, vidimo da im se prijatne emocije smanjuju, kao i optimistima (takođe ne značajno). Podaci o raspoloženju zajedno govore da se neprijatne emocije kod pesimista neznatno smanjuju, ali da se smanjuju i prijatne emocije. Moguće je da se neprijatne smanjuju zbog gore pomenute drugačije perspektive koju oni sada imaju, a pozitivne zbog gledanja isečka koji prikazuje loša i veoma neprijatna iskustva drugih osoba.

$\mathrm{Na}$ kraju, rezultati ovog rada pokazuju da postoje statistički značajne razlike između optimista i pesimista u izraženosti prijatnih emocija pre gledanja odlomka iz filma. Naime, prijatne emocije izmerene pre gledanja odlomka iz filma izraženije su kod optimista. Povezujući ove podatke sa podacima iznetim u prethodnim tabelama možemo da primetimo da su prijatne emocije pre gledanja filma izraženije kod optimista nego kod pesimista, što se i moglo očekivati. Međutim, takođe vidimo da se optimisti i pesimisti ne razlikuju međusobno u pogledu izraženosti prijatnih emocija posle gledanja isečka iz filma, što znači da se prijatne emocije kod optimista smanjuju i da im se, samim tim, raspoloženje kvari, dok ovakav efekat ne postoji kod pesimista. Ovo se može objasniti time što je raspoloženje kod pesimista prirodno sniženo, time što oni, po samoj definiciji ovog konstrukta stvari oko sebe već opažaju negativno, pa je teže da im bilo šta dodatno pokvari njihovo već sniženo raspoloženje. Kako nema prethodnih radova koji ispituju direktno indukciju afekta kod optimista i pesimista, u ovoj interpretaciji se i ne možemo pozvati na njih, ali se možemo pozvati na rad koji je ispitivao razlike u rešavanju zadataka, koji je pokazao da pesimisti bolje funkcionišu onda kada im se indukuje neprijatno raspoloženje, za razliku od optimista koji su bolji onda kada im se indukuje prijatno raspoloženje (Sanna, 1998). Dakle, ako pesimisti već bolje funkcionišu onda kada im se indukuje neprijatno raspoloženje, koje pritom stvara kod njih i neka pozitivna preispitivanja (prefraktalno ispitivanje sebe “šta bi moglo biti”), moguće je uzeti u obzir i ovu našu pretpostavku da pesimisti, onda kada im se prezentuju neprijatni filmski stimulusi, izlaze iz svoje negativne perspektive sveta i počinju da razmišljaju drugačije, što onda može dovesti upravo i do boljeg rešavanja zadataka od strane pesimista, dokazanog u prethodnim radovima, onda kada im se prezentuju upravo ovakvi stimulusi (Sanna, 1998). Ovakvi rezultati se mogu objasniti i "emotivnim paradoksom", koji se odnosi na uživanje publike u tužnim filmovima (Schramm \& Wirth, 2010). Nai-

\footnotetext{
${ }^{4}$ Preuzeto sa https://en.wikipedia.org/wiki/Schadenfreude
} 
me, raniji radovi ukazuju na to da su osobe koje su sklonije empatiji, osobe ženskog pola i još neki delovi populacije sklonije uživanju u tužnim filmovima (Schramm \& Wirth, 2010), pa je sasvim moguće da ovakav fenomen postoji i kod pesimista.

Takođe, vidimo da se provodljivost kože u oba slučaja menja, i da je promena paralelna opadanju prijatnih emocija, što bi moglo da nam govori da provodljivost kože prati opadanje ovih emocija, i da, samim tim, zapravo pokazuje opadanje dobrog raspoloženja kod ispitanika.

Dakle, na osnovu rezultata možemo da izvedemo zaključak da se raspoloženje pod uticajem neprijatnog filmskog stimulusa više menja kod optimista nego kod pesimista, dok se provodljivost kože, verovatno kao rezultat arauzala izazvanog filmskim stimulusom, menja kod obe grupe ispitanika.

\section{Zaključak}

Iz rezultata ovog rada možemo da zaključimo da se raspoloženje optimista, posle gledanja isečka iz filma usmerenog na indukciju neprijatnog afekta, menja više nego raspoloženje optimista. Preciznije, raspoloženje optimista se više „kvari“ posle gledanja pomenutog isečka iz filma. Iz ovoga možemo da zaključimo da su rezultati prethodnih radova koji govore o tome da film može da indukuju neprijatan afekat potvrđuju (Brown et al., 1977, prema Hagemann et al., 1999; Engel et al., 1984; Pillard et al., 1974; van Rooijen and Vlaander, 1984), a takođe i rezultati onih radova koji govore o tome da film može da dovede ne samo do psiholoških, već i do fizioloških promena kod njegovih gledalaca (Gross \& Levenson, 1995; Mewborn \& Rogers, 1979). Ono što je novo u ovom radu u odnosu na prethodne, vezano je upravo za optimizam i pesimizam. Naime, u našem radu se pokazalo da je indukcija afekta različita za ove dve podgrupe našeg uzorka. S obzirom na ovaj podatak, u narednim radovima koji se bave indukcijom afekta, trebalo bi voditi računa i o ovoj varijabli koja bi mogla biti konfundirajuća u ovakvim istraživanjima ukoliko se ne kontroliše.

Teorijski značaj ovog istraživanja ogleda se u boljem i dubljem upoznavanju toga na koji način optimisti i pesimisti reaguju na filmske stimuluse, kao i potvrdom rezultata koji govore o tome da je film u stanju da indukuje emocije kod svojih gledalaca.

Praktični značaj može se ogledati u korišćenju filma kao vrste umetnosti u svrhe korisne za svakodnevni život. Na primer, pošto je pokazano da film ostvaruje efekat na emocije svojih gledalaca, možemo ga koristiti kao sredstvo smanjivanja predrasuda prema određenim grupacijama ljudi, upravo kroz buđenje emocije prema tim grupama ljudi. Na primer, film iz koga je isečak za ovo istraživanje uzet se bavi progonima Jevreja, i možemo očekivati da će doprineti smanjenju predrasuda prema toj grupi ljudi.

Nedostatak ovog istraživanja je, pre svega, mali uzorak tako da za naredna istraživanja predlažemo veći uzorak. Takođe nedostatak može biti i neravnomerna raspodela polova ispitanika, pa za naredna istraživanja predlažemo uključivanje jednakog broja žena i muškaraca u uzorak. Takođe, za naredna istraživanja predlaže- 
mo i uključivanje glumaca i ispitivanje toga kako oni reaguju na filmske stimuluse. Pošto očekujemo da su glumci više naviknuti na filmske stimuluse, svakako preporučujemo uključivanje i kontrolne grupe ispitanika iz neglumačke populacije kao kontrolnu grupu i njihovo poređenje.

Za kraj možemo zaključiti da film zaista ostvaruje efekte na naš emotivni život, i to i na psihološkom i na fiziološkom planu. Usled toga smatramo važnim dalje izučavanje toga kakvi sve efekti filma mogu biti, koji su to pozitivni, a koji negativni efekti, radi boljeg upoznavanja jedne široko rasprostranjene umetnosti koja pretenduje da bude još jedan agens socijalizacije.

\section{Reference}

Appel, M., Krause, S., Gleich, U., \& Mara, M. (2016). Meaning Through Fiction: Science Fiction and Innovative Technologies. Psychology of Aesthetics, Creativity, and the Arts, 10(4), 472-480.

Arheim, R. (1993). Film as art. Berkley and Los Angeles, CA: University of California Press.

Ausbrooks, D. P., Thomas, S. P., \& Williams, R. L. (1995). Relationships among self efficacy, optimism, trait anger, and anger expression. Health Values, 19, $46-54$.

Boucsein, W. (1992). Electrodermal Activity. New York: Springer Science.

Bindge watching (2019, jul 10.). In Wikipedia. Preuzeto sa: https://en.wikipedia.org/wiki/ Binge-watching

Blankstein, K. R., Flett, G. L., \& Koledin, S. (1991). The brief College Student Hassles Scale: Development, validation and relation with pessimism. Journal of College Student Development, 3, 258-264.

Chang, E. C. (1998a). Dispositional optimism and primary and secondary appraisal of a stressor: Controlling for confounding influences and relations to coping and psychological and physical adjustment. Journal of Personality and Social Psychology, 74, 1109-1120.

Chang, E. C. (1998b). Does dispositional optimism moderate the relation between perceived stress and psychological well-being? A preliminary investigation. Personality and Individual Differences, 25, 233-240.

Critchley, H. D. (2002). Book Review: Electrodermal Responses: What Happens in the Brain. Neuroscientist, 8 (2), 132-142.

Davis, M. H., Hull, J. G., Young, R. D., and Warren, G. G. (1987). Emotional Reactions to Dramatic Film Stimuli: The Influence of Cognitive and Emotional Empathy. Journal of Personality and Social Psychology 52(1), 126-133.

Dziobek, I., Rogers, K., Fleck, S., Bahnemann, M., Heekeren, H. R., Wolf, O. T., \& Convit, A. (2008). Dissociation of cognitive and emotional empathy in adults with Asperger syndrome using the Multifaceted Empathy Test (MET). Journal of autism and developmental disorders, 38(3), 464-473. 
Edelberg, R. (1972). Electrical activity of the skin: Its measurement and uses in psychophysiology. In N.S. Greenfield \& R. A. Sternbach (Eds.), Handbook of psychophysiology (pp. 367 - 418). New York: Holt.

Engel, G. L., Frader, M., Barry, C., \& Morrow, G. (1984). Sadness evoked by a film on grief: An experimental study. International Journal of Psychiatry in Medicine, 14, 1-30.

Fontaine, K. R., \& Seal, A. (1997). Optimism, social support, and premenstrual dysphoria. Journal of Clinical Psychology, 53, 234-247.

Gross, J. J. \& Levenson, R. W. (1995). Emotion Elicitation Using Films. Cognition and Emotion, 9, 87-108.

Guarnera, S., \& Williams, R. L. (1987). Optimism and locus of control for health and affiliation among elderly adults. Journal of Gerontology, 43, 594-595.

Hagemann, D., Naumann, E., Maier, S., Becker, G., Luerken, A., Bartusse, D. (1999). The assessment of afective reactivity using flms: Validity, reliability and sex differences. Personality and Individual Differences, 26, 627-639.

Janjić, T. \& Goljović, N. (2018). Music and Movie Clip in Positive and Negative Mood Induction: Group Experimental Situation Outcomes [abstract]. In J. Todorović \& S. Đorić (Eds.) XIV Days of Applied Psychology, Book of Abstracts, September 2018, (pp.108), Niš: Faculty of Philosophy.

Jovanović, N. i Jovanović, T. F. (2005). Biofidbek-neurofidbek: osnovi metoda i oblasti primene. Beograd: Centar za primenjenu psihologiju.

Iguarta Perosanz, J. J., \& Paez Rovira, D. (1998). Validez y flabilidad de una escala de empatia e identificacion con los personajes. Psicothema, 10(2), 423-436.

Khoo, S., \& Bishop, G. D. (1997). Stress and optimism: Relationships to coping and wellbeing. Psychologia: An International Journal of Psychology in the Orient, 40, 29-40.

Kim, K., Bang, S., \& Kim, S. (2004) Emotion recognition system using short-term monitoring of physiological signals. Medical and biological engineering and computing, 42(3), 419-427.

Lanat'a, A., Valenza, G., \& Scilingo, E. P. (2012). A novel eda glove based on textileintegrated electrodes for affective computing. Medical \& biological engineering \& computing, 50(11), 1163-1172.

Long, B. C., Kahn, S. E., \& Schutz, R. W. (1992). Causal model of stress and coping: Women in management. Journal of Counseling Psychology, 39, 227-239.

Marshall, G. N., \& Lang, E. L. (1990). Optimism, self-mastery, and symptoms of depression in women professionals. Journal of Personality and Social Psychology, 59, 132-139.

Mayer, J. D., \& Gaschke, Y. N. (1988). The experience and meta-experience of mood. Journal of Personality and Social Psychology, 55, 102-111.

Mewborn, C. R., \& Rogers, R. W. (1979). Effects of threatening and reassuring components of fear appeals on physiological and verbal measures of emotion and attitudes. Journal of Experimental Social Psychology, 15(3), 242-253.

Nelson, E. S., Karr, K. A., \& Coleman, P. K. (1995). Relationships among daily hassles, optimism and reported physical symptoms. Journal of College Student Psychotherapy, 10, 11-26. 
O’Brien, W. H., Van Egeren, L., \& Mumby, P. B. (1995). Predicting health behaviors using measures of optimism and perceived risk. Health Values, 19(1), 21-28.

Philippot, P. (1993). Inducing and assessing differentiated emotion-feeling states in the laboratory. Cognition and Emotion, 7, 171-193.

Pillard, R. C., McNair, D. M., \& Fisher, S. (1974). Does marijuana enhance experimentally induced anxiety? Psychopharmacologia (Berl.), 40, 205-210.

Prokasy, W. F. \& Raskin, D. C. (1973). Electrodermal Activity in Psychological Research. New York: Academic Press.

Rijavec, M. i Ivanković, M. (2017). Dispozicijski optimizam i pesimizam kao prediktori školskoga uspjeha, ciljnih orijentacija u učenju, straha od ispitivanja i životnoga zadovoljstva učenika. Napredak, 158(4) 397-417.

Rottenberg, J., Ray, R. D., \& Gross, J. J. (2007). Emotion Elicitation Using Films. In J. A. Coan, \& J. J. B. Allen (Eds.), The Handbook of Emotion Elicitation and Assessment (pp. 9-28). London: Oxford University Press.

Sanna, L. J. (1998). Defensive pessimism and optimism: The bitter-sweet influence of mood on performance and prefactual and counterfactual thinking. Cognition $\&$ Emotion, 12(5), 635-665.

Schadenfreude (2019, Jul 10). In Wikipedia. Retrieved from https://en.wikipedia.org/ wiki/Schadenfreude.

Scheier, M. F., Carver, C. S., \& Bridges, M. W. (1994). Distinguishing optimism from neuroticism (and trait anxiety, self-mastery, and self-esteem): a reevaluation of the Life Orientation Test. Journal of Personality and Social Psychology, 67(6), 1063-1078

Scheier, M. F., Weintraub, J. K., \& Carver, C. S. (1986). Coping with stress: Divergent strategies of optimists and pessimists. Journal of Personality and Social Psychology, 51(6), 1257-1264.

Schramm, H., \& Wirth, W. (2010). Exploring the paradox of sad-film enjoyment: The role of multiple appraisals and meta-appraisals. Poetics, 38(3), 319-335.

Schuller, I. S. (1995). Cognitive style categorization width and anxiety. Studia Psychologica, 37, 142-145.

Silverthorn, D. U. (2009). Human Physiology: An Integrated Approach (4 ed.). Boston: Pearson/Benjamin Cummings.

Sumi, K., Hofie, K., \& Hayakawa, S. (1997). Optimism, Type A behavior, and psychological well-being in Japanese women. Psychological Reports, 80, 43-48.

Statista Research Department (2018). Tv daily viewing time in Europe. Retrieved from https://www.statista.com/statistics/422719/tv-daily-viewing-time-europe/

Sweetman, M. E., Munz, D. C., \& Wheeler, R. J. (1993). Optimism, hardiness, and explanatory style as predictors of general well-being among attorneys. Social Indicators Research, 29, 153-161.

Tannenbaum, P. H. \& Gaer, E. P. (1965). Mood changes as a function of stress of protagonist and degree of identification in a film-viewing situation. Journal of Personality and Social Psychology, 2(4), 612-616.

Thought Technology [Apparatus and software]. (2007). BioGraph Infiniti Quick Start Guide. Montreal: Thought Technology Ltd. 
van Rooijen, L., \& Vlaander, G. P. J. (1984). Dramatic induction of depressed mood. Journal of Clinical Psychology, 40, 1318-1322.

Wagner, H. L. (1990). The spontaneous facial expression of differential positive and negative emotions. Motivation and Emotion, 14, 27-43

\author{
Ana Jovančevićs \\ Miljan Jović \\ Nebojša Milićević \\ Miodrag Milenović \\ Miroslav Komlenić \\ Department of Psychology, \\ Faculty of Philosophy, \\ University of Niš
}

\title{
SKIN CONDUCTANCE AND CHANGES IN POSITIVE AND NEGATIVE AFFECT INDUCED BY WATCHING MOVIE CLIP IN RELATION WITH OPTIMISM AND PESSIMISM
}

\begin{abstract}
The aim of this paper is to investigate the relation between psychogalvanic reflex and unpleasant affect induced by film, as well as the difference between optimists and pessimists regarding the induction of unpleasant affect. The sample consisted of 42 students from the Faculty of Philosophy in Niš (male, $n=4$; female, $n=38)$ aged 18 to $20(M=19, S D=0.54)$. The following instruments were used: the revised life orientation scale (LOT-R), a brief mood introspection scale (BMIS), and eight-channel polygraph ProComp Infiniti version 4.0. Stimulus was a clip from the film "Sophie's Choice". Respondents watched a neutral stimulus before film clip, used as a control measure for recording the basic level of skin conductance of the respondents. The data were analysed by $t$-test for independent samples (for differences between optimists and pessimists) and $t$-test for dependent samples (for differences before and after viewing the clip). From the results we can conclude that the mood of optimists, after watching a film clip aimed at induction of unpleasant affect, changes more than the mood of pessimists $(p=.000)$. More precisely, the mood of optimists is more "spoiled" after watching the movie clip, while the mood of pessimists does not change statistically significantly ( $p=$ .367). Skin conductance is statistically significant in both optimists $(p=.001)$ and pessimists $(p=.005)$. We can conclude that the induction of affect was different for these two subsamples. In view of this fact, in the subsequent papers researching affect induction, this potentially confunding variable should be taken into account.
\end{abstract}

Key words: Optimism-Pessimism, Film, Emotion induction, Negative affect, Skin conductance.

Primljeno: 29.05.2019.

Primljena korekcija: 14.07.2019.

Prihvaćeno za objavljivanje: 05.08.2019.

${ }^{5}$ ana.jovancevic@filfak.ni.ac.rs 